\title{
Strain growth in a finite-length cylindrical shell under internal pressure pulse
}

DOI:

$10.1115 / 1.4035696$

\section{Document Version}

Accepted author manuscript

Link to publication record in Manchester Research Explorer

\section{Citation for published version (APA):}

Dong, Q., Li, Q. M., \& Zheng, J. (2017). Strain growth in a finite-length cylindrical shell under internal pressure pulse. Journal of Pressure Vessel Technology, Transactions of the ASME. https://doi.org/10.1115/1.4035696

\section{Published in:}

Journal of Pressure Vessel Technology, Transactions of the ASME

\section{Citing this paper}

Please note that where the full-text provided on Manchester Research Explorer is the Author Accepted Manuscript or Proof version this may differ from the final Published version. If citing, it is advised that you check and use the publisher's definitive version.

\section{General rights}

Copyright and moral rights for the publications made accessible in the Research Explorer are retained by the authors and/or other copyright owners and it is a condition of accessing publications that users recognise and abide by the legal requirements associated with these rights.

\section{Takedown policy}

If you believe that this document breaches copyright please refer to the University of Manchester's Takedown Procedures [http://man.ac.uk/04Y6Bo] or contact uml.scholarlycommunications@manchester.ac.uk providing relevant details, so we can investigate your claim.

\section{OPEN ACCESS}




\title{
Strain Growth in a Finite-Length Cylindrical
}

\section{Shell under Internal Pressure Pulse}

\author{
Qi Dong \\ Institute of Chemical Materials, China Academy of Engineering Physics \\ PO Box 919-319, Mianyang 621999, P. R. China \\ dongqi@caep.cn
}

Q.M. Li ${ }^{1}$

School of Mechanical, Aerospace and Civil Engineering, Pariser Building

The University of Manchester, Manchester M13 9PL, UK;

State Key Laboratory of Explosion Science and Technology,

Beijing Institute of Technology, Beijing 100081, P.R.China

qingming.li@manchester.ac.uk

\section{Jinyang Zheng}

Institute of Chemical Machinery and process equipment

Zhejiang University, Hangzhou 310027, P.R.China

jyzh@zju.edu.cn

\footnotetext{
${ }^{1}$ Corresponding author
} 
ASME Journal of Pressure Vessel Technology

\section{ABSTRACT}

Strain growth is a phenomenon observed in the elastic response of containment vessels subjected to internal blast loading. The local dynamic response of a containment vessel may become larger in a later stage than its response in the earlier stage. In order to understand the possible mechanisms of the strain growth phenomenon in a cylindrical vessel, dynamic elastic responses of a finite-length cylindrical shell with different boundary conditions subjected to internal pressure pulse are studied by finite element simulation using LS-DYNA. It is found that strain growth in a finite-length cylindrical shell with sliding-sliding boundary conditions is caused by nonlinear modal coupling. Strain growth in a finite-length cylindrical shell with free-free or simply-supported boundary conditions is primarily caused by linear modal superposition, possibly enhanced by nonlinear modal coupling. The understanding of these strain growth mechanisms can guide the design of cylindrical containment vessels.

Keywords: Strain Growth; Cylindrical Shell; Linear Modal Superposition; Nonlinear Modal Coupling 


\section{Introduction}

Containment vessels have been widely used to contain the blast effects in both civil and military applications. Strain growth is a phenomenon observed in the elastic response of containment vessels subjected to internal blast loading. The local dynamic response of a containment vessel may become larger in a later stage than its response in the earlier stage, which was first reported by Buzukov [1] in a cylindrical chamber subjected to internal blast loading from linear explosives.

Since it was first reported four decades ago [1], the strain growth phenomenon has attracted great attention in the design and use of containment vessels, and several mechanisms have been proposed to explain this interesting phenomenon in both cylindrical and spherical shells. As reflected waves after the first peak of the blast shock wave may still be very strong, strain growth was attributed to the possible resonance between reflected shock waves and the vibrations of cylindrical [2] and spherical [3] shells. Karpp et al. [4] and Abakumov et al. [5] showed that bending responses could be excited by the structural perturbation from the flanges and thus drastic strain amplification might be caused. Dong et al. [6] showed that the blast loading history in containment vessels can be divided into three periods, i.e. the primary-shock period, the shock-reflection period and the pressure oscillation period, in which reflected waves in the second period could cause strain growth of shells. Other researchers proposed that the superposition or beating of various vibration modes with close frequencies is responsible for strain growth in cylindrical [1, 7, 8, 9] and spherical [10-12] containment vessels. Detailed studies on strain growth in the literature were summarized in Li et al. [13]. It has recently been realized that the coupling between the breathing and bending modes, which 
are excited by the dynamic unstable vibration, is another cause for strain growth of rings (or the in-plane response of cylindrical shells) [14] and spherical shells [15]. However, these conclusions cannot be directly extended to a finite-length cylindrical vessel which is the mostly used type of explosion containment vessels in practice.

In the present study, the mechanisms of strain growth are investigated in a finitelength thin-walled cylindrical shell subjected to uniformly-distributed internal pressure pulse. Compared to the in-plane response of a cylindrical shell which corresponds a plane-strain ring in Li et al. [14], the response of a finite-length cylindrical shell with different boundary conditions in the current study is more complicated with the consideration of out-plane response. The material properties and structural dimensions of the cylindrical shell studied in the paper are listed in Tables 1 and 2, respectively. The structural dimensions of the studied shell in this paper are the same as those of chamber-1 in experiments reported in [8], in which the strain growth phenomenon was observed when chamber-1 was subjected to blast loading from linear explosives.

In this paper, we only concern mechanisms of strain growth caused by the primary shock, and the blast loading is simplified as a transient triangular pressure pulse $P(t)$,

$$
\begin{array}{r}
p(t)=P(1-t / T), 0<t \leq T \\
p(t)=0, t>T
\end{array}
$$

where $P$ is the peak overpressure, $t$ is the time and $T$ is the duration of the transient pressure. Therefore, the blast loading from linear explosives on chamber-1 in [8] is simplified as a uniformly-distributed pressure pulse.

In this study, by employing finite element simulation with dynamic analysis software LS-DYNA [15, 16], the dynamic response characteristics of a finite-length 
cylindrical shell with sliding-sliding, free-free and simply-supported boundary conditions are investigated in Sections 2, 3 and 4, respectively, followed by conclusions in Section 5.

\section{Strain growth in a sliding-sliding cylindrical shell}

In this section, the dynamic response of the sliding-sliding cylindrical shell subjected to uniformly-distributed internal pressure pulse is presented in breathing mode response stage and nonlinear modal coupling response stage. For a cylindrical shell with sliding-sliding boundary conditions, the axial motions of the both ends are fixed.

In the finite element analysis on the dynamic responses of the shell in LS-DYNA, all the cylindrical shells are built using three-dimensional models with solid elements. The shell is meshed into 12, 96 and 36 parts in the radial, circumferential and axial directions, respectively. Convergence tests have shown that the above mesh size can obtain reasonable results. Additionally, in all the FE models of this study, the time step is $1 \mu \mathrm{s}$, which is small enough to capture the peak values.

\subsection{Breathing mode response in a sliding-sliding cylindrical shell}

For an infinite axisymmetric cylindrical shell subjected to a uniformly-distributed blast loading, its early elastic response is dominated by the breathing mode vibration and thus it can be simplified as an axisymmetric single degree of freedom (SDoF) model, i.e. radial displacement, which is independent of coordinates, is the only degree of freedom.

Among the concerned cylindrical shells with different boundary conditions, the pure breathing mode response happens only in the cylindrical shells with sliding-sliding boundary conditions. Therefore, the sliding-sliding cylindrical shell is first studied in this paper. 
The frequencies of the breathing mode in plane-strain and plane-stress cylindrical shells are

$$
f_{0}=\frac{1}{2 \pi a} \sqrt{\frac{E}{\rho\left(1-v^{2}\right)}},
$$

and

$$
f_{1}=\frac{1}{2 \pi a} \sqrt{\frac{E}{\rho}} .
$$

respectively, where $a$ is radius, $E$ is Young's Modulus, $\rho$ is the density and $v$ is Poisson's ratio.

The plane-stress response of cylindrical shells is based on Dumchuk's onedimensional cylindrical shell model [17]. The calculated plane-strain and plane-stress breathing mode frequencies of the cylindrical shell are $4107.7 \mathrm{~Hz}$ and $3878.3 \mathrm{~Hz}$, respectively.

The breathing mode response of the studied shell with sliding-sliding boundary conditions subjected to a transient pressure pulse is shown in Figs. 1 (a) and (b) from finite element simulation results (the first peak strain is 0.001). In the present study, the first peak strain is defined as the maximum strain (i.e. the ratio of the maximum radial displacement to the radius) in the first vibration period. The deformed shape of the shell in Fig. 2 demonstrates that only breathing mode shape is observed in the whole process. It is noted that the displacement of deformed shapes in this paper has been multiplied by 10 to make the motion visible.

It has been shown that the dynamic response of a containment vessel in the initial stage agrees well with the calculation by employing the breathing mode response model, which, however, cannot predict the strain growth in the later stage. 


\subsection{Nonlinear modal coupling response in a sliding-sliding cylindrical shell}

When the studied shell with sliding-sliding boundary conditions was subjected to higher impulsive loading, a late-time increase of displacement was observed in LSDYNA simulation. The response histories at the middle section of the outer surface on the sliding-sliding shell are presented in Figs.3, 4 and 5, which show very similar characteristics to the strain growth phenomenon observed in plane-strain rings [13].

Figures 3-5 show that the response of the sliding-sliding shell in the earlier stage is a plane-strain breathing mode vibration. However, after multiple cycles of vibration with the same amplitude, radial displacement-time history in Fig. 3(a) shows that the response grows from the first peak strain to a higher value. As shown in Fig. 3(b), the frequency spectrum of the radial response curve confirms that some vibration modes other than the breathing mode were excited, and the frequencies of those excited modes (i.e. $f_{b}$ ) are approximately half of the breathing mode frequency (i.e. $f_{0}$ ). Additionally, circumferential and axial displacement-time histories in Figs. 4 and 5 show that circumferential and axial displacements grow from very low values to peak values during the strain growth stage due to the bending effects, in which some other modes participate in the vibration.

In the earlier stage, the deformed shape of the cylindrical shell is the same as that in Fig. 2. However, in the later stage when strain growth happens, non-axisymmetric responses are observed in the deformed shape in Fig. 6. The response characteristics of the current sliding-sliding cylindrical shell show very similar characteristics to the strain growth phenomenon observed in plane-strain rings in $\mathrm{Li}$ et al. [13], in which the nonlinear modal coupling between breathing mode and non-axisymmetric modes is 
proposed as the mechanism of strain growth. Compared to the radial and circumferential responses in plane-strain rings in $\mathrm{Li}$ et al. [13], there is an axial response in cylindrical shells in the current study, leading to more complex vibration modes and dynamic response of cylindrical shells. Modal analysis on the cylindrical shell was conducted by ANSYS, and a typical non-axisymmetric mode shape for $n=3, m=3$ is presented in Fig. 7, in which $n$ is circumferential wave number and $m$ is longitudinal half-wave number. It is noted that non-axisymmetric modes that involve in nonlinear model coupling in this study are the so-called 'coupled radial-axial modes' $(n=2,3,4 \ldots)$ in Blevins [18].

It was found that the above simulation phenomenon is similar to the numerical Mathieu solution of the dynamic unstable vibration in a cylindrical shell subjected to a nearly uniform radial impulse [19], which indicates that strain growth observed in LSDYNA can be explained by the nonlinear modal coupling theory proposed by McIvor and Lovell [19]. The initial response of a finite-length sliding-sliding cylindrical shell under perfectly uniform radial impulse is the breathing mode response discussed in Section 2.1. However, in the presence of small non-uniformities in the impulse or structure, some bending modes can be parametrically excited to rather large amplitudes, and the nonlinear coupling between the breathing mode and bending modes may happen [19]. The bending modes reported in McIvor and Lovell [19] are the non-axisymmetric modes discussed above and demonstrated in Fig. 7. If the frequency of a bending mode is close to half of the breathing mode frequency, this bending mode may become unstable and undergo significant growth, as shown in Figs. 4 and 5. Therefore, it may be concluded that strain growth of the sliding-sliding cylindrical shell in Fig. 3(a) is caused 
by nonlinear modal coupling between the breathing mode and unstable non-axisymmetric modes.

The strain growth phenomenon was also observed in the shell subjected to higher impulsive loadings, as shown in Fig. 8 when the first peak strain is 0.01 . Responses of the shell subjected to different impulses are summarized in Table 3, in which the first peak strains of the shell are $0.006,0.008$ and 0.010 . Strain growth factor is defined as the ratio of the maximum radial displacement in the whole vibration to the first peak radial displacement, and strain growth time is the duration from the beginning to the moment when the maximum radial displacement appears. Table 3 shows that strain growth time decreases as the first peak strain increases. However, the strain growth factors of the shell subjected to different impulses vary in a narrow range between 2.6 and 3.0.

\section{Strain growth in a free-free cylindrical shell}

In this section, the dynamic response of the free-free cylindrical shell subjected to uniformly-distributed internal pressure pulse is presented in linear modal superposition response stage and nonlinear modal coupling response stage. For a cylindrical shell with free-free boundary conditions, both ends of the shell are completely free.

\subsection{Linear modal superposition response in a free-free cylindrical shell}

The dynamic response of the studied shell with free-free boundary conditions subjected to impulsive loading was calculated in LS-DYNA, as shown by the radial response at the middle section of the outer surface of the shell in Fig. 9 and Table 4, in which the first peak strain is 0.001 . Unlike the one-dimensional response in the slidingsliding shell, the response of the free-free shell behaves as a beating phenomenon, as presented by Fig. 9(a), and the strain growth phenomenon occurs, in which the strain 
growth factor in this response is 1.762 , as shown in Table 4 . The frequency spectrum in Fig. 9(b) shows that three modes dominantly participate in the response, and the frequencies of these modes are $2834.7 \mathrm{~Hz}, 3810.5 \mathrm{~Hz}$ and $4396.7 \mathrm{~Hz}$, respectively.

The deformed shape of the cylindrical shell is presented in Fig. 10, which shows that the response is axisymmetric and the modes involved are axisymmetric modes (i.e. $n=0$ ). It was also observed that the radial displacement-histories of different points at different sections of the cylindrical shell are very close, which demonstrates that the response in the first quarter period is dominated by one-dimensional response i.e. breathing mode response. The vibration frequency $3810.5 \mathrm{~Hz}$ observed in simulation is close to the value 3873.3 Hz predicted by the plane-stress frequency Eq. (3), which also supports that the response in the first quarter period is a mainly plane-stress breathing mode response. The other frequencies observed in Fig. 9(b) are 2834.7 Hz and 4396.7 Hz, respectively, which are close to the values $2857.7 \mathrm{~Hz}$ and $4374.0 \mathrm{~Hz}$ i.e. the frequencies of the axisymetric modes for $n=0$ and $m=1$ obtained by modal analysis with ANSYS. It is noted that axisymmetric modes in this study correspond to the so-called coupled axial-radial modes $(n=0)$ in Blevins [19]. The mode with the frequency of $2834.7 \mathrm{~Hz}$ is axially dominant vibration mode ( $n=0$ and $m=1$ ) and the mode with the frequency of $4396.7 \mathrm{~Hz}$ is radially dominant vibration mode ( $n=0$ and $m=1$ ), as labeled by $f_{\mathrm{a}}$ and $f_{\mathrm{r}}$ in Fig. $9(\mathrm{~b})$, respectively. The excitation of axisymmetric modes of the shell in Fig. 9 is due to the lack of axial restrain from the free-free boundary condition, and thus strain growth of the shell in Fig. 9 is caused by the linear superposition of the breathing mode and axisymmetic modes, which is different from the nonlinear coupling of the breathing mode and nonaxisymmetric modes. 
The dynamic response of the shell with a first peak strain 0.003 was also calculated by LS-DYNA, which shows a very similar vibration characteristic as that in Fig. 9(a) when the first peak strain of Shell 1 is 0.001 . When the one third of radial displacements of the shell with first peak strain 0.003 are plotted in the response history, the curve is exactly the same as the radial displacement-time history of the shell with first peak strain of 0.001 , as shown in Fig. 11. Therefore, unlike the nonlinear modal coupling observed from Figs. 3(a) and 8(a) in which the responses of the shell with different pressure pulses vary nonlinearly as the first peak strains change, the modal superposition in this response demonstrates a linear characteristic i.e. the responses of shells under different first peak strains vary proportionally as the first peak strains change.

\subsection{Nonlinear modal coupling response in a free-free cylindrical shell}

Section 3.1 shows that the response of the free-free shell is a linear modal superposition response, when the first peak strain is 0.001 . However, when the shell was subjected to larger impulsive loading, another different response was observed in LSDYNA, as presented in Fig. 12, in which the first peak strain is 0.006. Fig. 12(a) shows that in the later stage, a higher response appears after the linear modal superposition response stage, and Fig. 12(b) shows that some vibration modes with about half breathing mode frequency are excited. The deformed shape of the shell in the later stage is presented in Fig. 13. The phenomenon observed in the later stage is similar as that observed in the sliding-sliding cylindrical shells, which demonstrates that nonlinear modal coupling occurs in the free-free cylindrical shell when the first peak strain is 0.006 . As shown in Table 5, the strain growth factor in Fig. 12(a) is 3.365, which is larger than the value of 1.762 in Table 4 that is simply due to the linear modal superposition. 
In the sliding-sliding cylindrical shell, the nonlinear modal coupling is caused by the coupling between the breathing mode and non-axisymmetric modes. However, in freefree cylindrical shells, not only the breathing mode, but also the axisymmetric modes are involved in the nonlinear modal coupling with the non-axisymmetic modes, which makes the present problem more complicated.

The dynamic responses of the shell with free-free boundary conditions subjected to different pressure pulses were calculated by LS-DYNA, as shown in Table 5. Compared to Table 3, Table 5 shows that strain growth factor in the free-free cylindrical shell is higher than those in the sliding-sliding cylindrical shell, which may be explained by the strain amplification due to the linear modal superposition in the earlier stage of the freefree cylindrical shell.

Based on the study in this section, it can be found that strain growth in the free-free cylindrical shell is primarily caused by the linear modal superposition in the earlier stage, and possibly enhanced by nonlinear modal coupling in the later stage.

\section{Strain growth in a simply-supported cylindrical shell}

In this section, the dynamic response of the simply-supported cylindrical shell subjected to uniformly-distributed internal pressure pulse is presented in linear modal superposition response stage and nonlinear modal coupling response stage. For a cylindrical shell with simply-supported boundary conditions, the radial and circumferential motions of the both ends are fixed.

The dynamic response of the cylindrical shell with simply-supported boundary conditions subjected to uniformly-distributed impulsive loading was also calculated in LS-DYNA, as shown in Fig. 14. The linear modal superposition response and nonlinear 
modal coupling response are also observed in the shell with simply-supported boundary conditions in Fig. 14, which is very similar to the response characteristics of the shell with free-free boundary conditions in Fig. 12. According to the understanding on the mechanisms of strain growth in Fig. 12, it can be proposed that the strain growth in the shell with simply-supported boundary conditions is primarily caused by linear modal superposition, and enhanced by nonlinear modal coupling in the later stage.

A real cylindrical explosion containment vessel consists of three parts, i.e. the finitelength cylindrical shell and the two end enclosures connected by flanges. If the flanges and the end enclosures are small, the axial and radial restrains to the finite-length cylindrical shell are relatively small, and therefore, the finite-length cylindrical model with free-free boundary conditions may represent the containment vessel. On the other hand, if the flanges and end enclosures are large, they have large restrains to the finitelength cylindrical shell, and thus, the finite-length cylindrical shell model with simplysupported boundary conditions is applicable. However, it should be realized that the freefree boundary condition underestimates the restrains of the small flanges and end enclosures while the simply-supported boundary condition overestimates the restrains of the large flanges and end enclosures. Therefore, the dynamic response characteristics of a cylindrical containment vessel should be bounded by the behaviors of finite-length cylindrical shells with free-free and dimply-supported boundary conditions. The results obtained in this study can be used to guide the design of cylindrical explosion containment vessels.

\section{Experimental observations}


There are some reported experimental results on the dynamic responses of cylindrical containment vessels subjected to internal blast loading, which will be employed to support the analysis in this study.

Zhu [8] investigated the mechanism of strain growth through experiments on cylindrical explosive chambers with linear explosives distributed along the central axis. Cyclic strain growth was observed in Chamber-1 with linear explosives, as shown by the strain-time history in Fig.15(a) and the corresponding frequency spectrum in Fig.15(b). Fig.15(b) shows that the main vibration frequencies are 2.4, 3.6, 3.9, 4.0 and $4.2 \mathrm{kHz}$, respectively, in which $3.9 \mathrm{kHz}$ is the frequency of the plane-stress breathing mode in Chamber-1. In the present study, the structural dimensions of the studied cylindrical shell are the same as those of the cylindrical shell in Chamber-1. In the linear modal superposition stage, the calculated frequencies of the plane-stress breathing mode, the radially and axially dominant vibration modes are $3873.3,2856.3$ and $4370.9 \mathrm{~Hz}$ (i.e. 3.9, 2.9 and $4.4 \mathrm{kHz}$ ), respectively. The calculated natural frequencies of the vibration modes are close to those of vibration modes observed in experiments. Additionally, the frequency spectrums in Fig.9(b) from the simulation and Fig.15(b) from the experiment show similar characteristics. If the effects of the blast loading and structural perturbation in cylindrical chambers are considered, the agreement between the present analytical results and experimental investigation [8] could be reasonably good, which supports the present model and analyses according to the linear modal superposition theory.

Zhong [20] conducted experimental investigations on the dynamic responses of a cylindrical containment vessel with flat end plates, and the strain growth phenomenon is presented in Fig.16(a). According to this study, the calculated frequency of the plane- 
stress breathing mode is $827.72 \mathrm{~Hz}$, which can be observed from Fig.16(b). Zhong [20] found that in the frequency spectrum of Fig.16(b), the vibration modes with lower frequencies ranging from $100 \mathrm{~Hz}$ to $500 \mathrm{~Hz}$ are the nonaxisymmetric modes with $m=1-3$ and $n=2-6$, whose frequencies are around half of the breathing mode frequency. According to the nonlinear modal coupling theory in this study, the excited nonaxisymmetric modes are more likely caused by the nonlinear modal coupling, which has not been proposed by the researchers in the containment vessel community so far.

\section{Conclusions}

Strain growth in a finite-length cylindrical shell with different boundary conditions under internal pressure pulse is studied in this paper. Strain growth in a finite-length cylindrical shell with sliding-sliding boundary conditions is caused by the nonlinear modal coupling. Strain growth in a finite-length cylindrical shell with free-free or simplysupported boundary conditions is primarily caused by the linear modal superposition, possibly enhanced by the nonlinear modal coupling.

It is further demonstrated that the strain growth in a linear modal superposition response is caused by the superposition of the breathing mode and the axisymmetric modes, in which the responses of the shell with different pressure pulses vary proportionally as the first peak strains change. The strain growth in a nonlinear modal coupling response is caused by the coupling of the breathing mode and unstable nonaxisymmetric modes, in which the responses of the shell with different pressure pulses vary nonlinearly as the first peak strains change. The understanding of these different strain-growth mechanisms and their effective ranges is important for the safe design of cylindrical explosion containment vessels. 


\section{Acknowledgments}

The authors acknowledge the financial support from National Science Foundation of China (NSFC) under Grant Nos. 11372293, 11221202 and 11672272 and China Academy of Engineering Physics (CAEP) under Grant No. 2014-1-111.

\section{References}

[1] Buzukov AA. Characteristics of the behavior of the walls of explosion chambers under the action of pulsed loading. Fiz Goreniya Vzryva 1976;12(4):605-610.

[2] Buzukov AA. Forces produced by an explosion in an air-filled explosion chamber. Fiz Goreniya Vzryva 1980;16(5):87-93.

[3] Zhdan SA. Dynamic load acting on the wall of an explosion chamber. Fiz Goreniya Vzryva 1981;17(2):142-146.

[4] Karpp RR, Duffey TA, Neal TR. Response of containment vessels to explosive blast loading. LA-8082, Los Alamos National Laboratory, 1980.

[5] Abakumov AI, Egunov VV, Ivanov AG, Uchaev AA, Tsypkin VI, Shitov AT. Calculation and experiments on the deformation of explosion-chamber shells. Zhurnal Prikladnoi Mekhaniki i Tekhnicheskoi Fiziki 1984;(3):127-130.

[6] Dong Q, Li QM and Zheng JY. Interactive mechanisms between the internal blast loading and the dynamic elastic response of spherical containment vessels. Int. J. of Impact Eng 2010;37(4):349-358.

[7] Kornev VM, Adishchev VV, Mitrofanov AN, Grekhov VA. Experimental investigation and analysis of the vibrations of the shell of an explosion chamber. Fiz Goreniya Vzryva 1979;15(6):155-157. 
[8] Zhu WH. Theoretical and experimental investigations on the dynamic response of cylindrical explosive chamber. Ph. D thesis. Natl. Univ. of Defence Tech. 1994. (in Chinese)

[9] Zhu WH, Xue HL, Zhou GQ, Schleyer GK. Dynamic response of cylindrical explosive chambers to internal blast loading produced by a concentrated charge. Int. J. Impact Eng 1997;19:831-845.

[10] Mal'tsev VA, Konon YA, Adishchev VV, Kornev VM. Experimental study and analysis of the vibrations of an impulsively loaded thin-walled spherical shell. Fiz Goreniya Vzryva 1984;20(2):97-102.

[11] Belov AI, Klapovskii VE, Kornilo VA, Mineev VN, Shiyan VS. Dynamics of a spherical shell under a nonsymmetric internal pulse loading. Fiz Goreniya Vzryva 1984;20(3):71-74.

[12] Duffey TA, Romero C. Strain growth in spherical explosive chambers subjected to internal blast loading. Int. J. Impact Eng 2003;28:967-983.

[13] Li QM, Dong Q, Zheng JY. Strain growth of the in-Plane response in an elastic cylindrical shell. Int. J. Impact Eng 2008;35:1130-1153.

[14] Dong Q, Li QM, Zheng JY. Further study on strain growth in spherical containment vessels subjected to internal blast loading. Int. J. Impact Eng 2010;37:196-206.

[15] Livermore Software Technology Corporation. LS-DYNA theoretical manual, 1998.

[16] Livermore Software Technology Corporation. LS-DYNA keyword user's manual (Version 970), 2003.

[17] Demchuk AF. Method for designing explosion chambers. Zhurnal Prikladnoi Mekhaniki i Tekhnicheskoi Fiziki 1968;9(5):47-50. 
[18] Blevins RD. Formulas for Natural Frequency and Mode Shape. Krieger: Malabar; 1984.

[19] McIvor IK and Lovell EG. Dynamic response of finite-length cylindrical shells to nearly uniform radial impulse. AIAA J. 1968;6:2346-2351.

[20] Zhong FP. Theoretical and experimental investigations on the elasto-plastic response of double-layered cylindrical explosion containment vessels, Ph. D thesis. University of Science and Technology of China. 1999. (in Chinese) 


\section{Figure Captions List}

Fig. 1 (a) Radial displacement-time history of the response at the middle section of the sliding-sliding shell subjected to pressure pulse (first peak strain is 0.001), (b) The frequency spectrum of the curve in Fig. 1(a)

Fig. 2 The deformed shape of the sliding-sliding shell subjected to pressure pulse (first peak strain is 0.001) (The displacement has been multiplied by 10)

Fig. 3 (a) Radial displacement-time history of the response at the middle section of the sliding-sliding shell subjected to impulsive loading (first peak strain is 0.006), (b) The frequency spectrum of the curve in Fig. 3(a)

Fig. 4 Circumferential displacement-time history of the response at the middle section of the sliding-sliding shell subjected to impulsive loading (first peak strain is 0.006 )

Fig. 5 Axial displacement-time history of the response at the middle section of the sliding-sliding shell subjected to impulsive loading (first peak strain is $0.006)$

Fig. 6 The deformed shape of the sliding-sliding shell subjected to pressure pulse (first peak strain is 0.006) (The displacement has been multiplied by 10)

Fig. 7 (a) Mode shape of the coupled radial-axial modes for $n=3, m=3$, (b) circumferential nodal pattern and (c) axial nodal pattern

Fig. 8 Radial displacement-time history of the response of Shell 1 (SlidingSliding B.C.) subjected to impulsive loading (first peak strain is 0.01), (b) The frequency spectrum of the curve in Fig.8(a). 
Fig. 9 (a) Radial displacement-time history of the response at the middle section of the free-free shell subjected to impulsive loading (first peak strain is 0.001), (b) The frequency spectrum of the curve in Fig. 9(a)

Fig. 10 The deformed shape of the free-free shell subjected to pressure pulse (first peak strain is 0.001) (The displacement has been multiplied by 10)

Fig. 11 Radial displacement-time history of the shell (first peak strain is 0.001) and one third of radial displacement-time history of the shell (first peak strain is 0.003).

Fig. 12 (a) Radial displacement-time history of the response at the middle section of the free-free shell subjected to impulsive loading (first peak strain is 0.006), (b) The frequency spectrum of the curve in Fig. 12(a)

Fig. 13 The deformed shape of the free-free shell subjected to pressure pulse (first peak strain is 0.006) (The displacement has been multiplied by 10)

Fig. 14 (a) Radial displacement-time history of the response at the middle section of the simply-supported shell subjected to impulsive loading (first peak strain is 0.006), (b) The frequency spectrum of the curve in Fig. 14(a)

Fig. 15 (a) A strain-time history of cylindrical explosive Chamber 1 with linear explosive $\mathrm{W}=27.3 \mathrm{~g}$ RDX, and (b) the frequency spectrum [8]

Fig. 16 (a) A strain-time history of a cylindrical containment vessel, and (b) the frequency spectrum [20] 
ASME Journal of Pressure Vessel Technology

\section{Table Caption List}

Table $1 \quad$ Material parameters of the cylindrical shell

Table 2 Structural dimensions of the cylindrical shell

Table 3 Responses of the sliding-sliding shell with different pressure pulses

Table $4 \quad$ Response of the free-free shell (first peak strain is 0.001 )

Table $5 \quad$ Response of the free-free shell with different pressure pulses 
ASME Journal of Pressure Vessel Technology

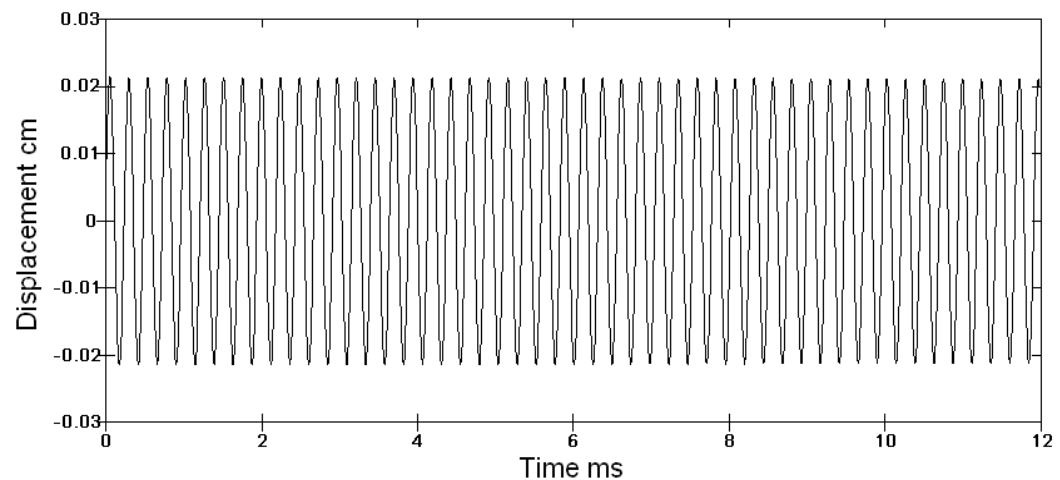

(a)

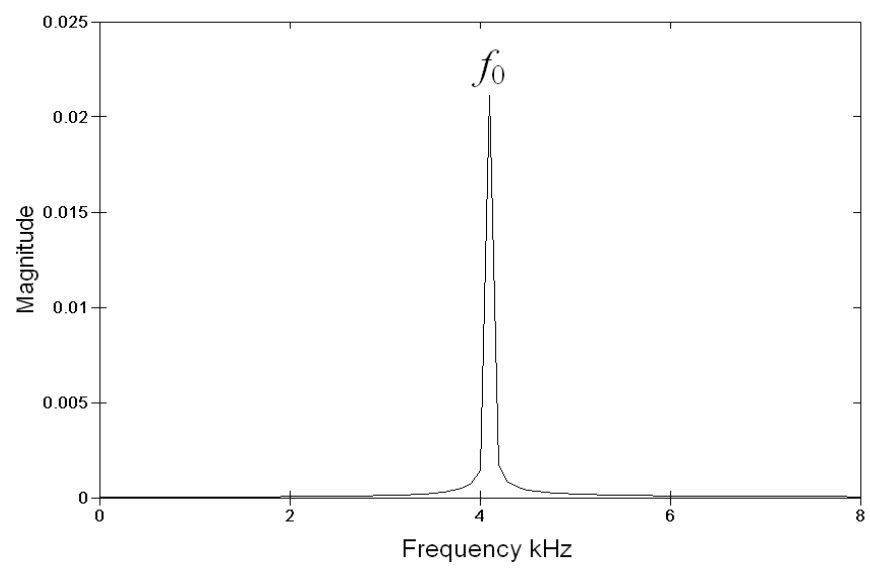

(b)

Fig. 1. 
ASME Journal of Pressure Vessel Technology

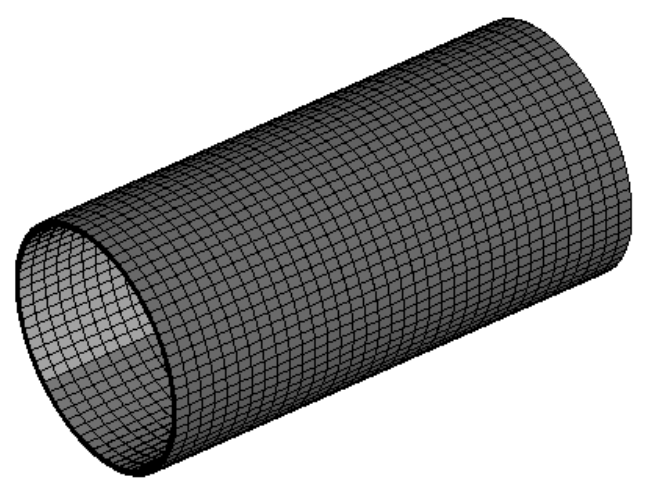

Fig. 2. 
ASME Journal of Pressure Vessel Technology

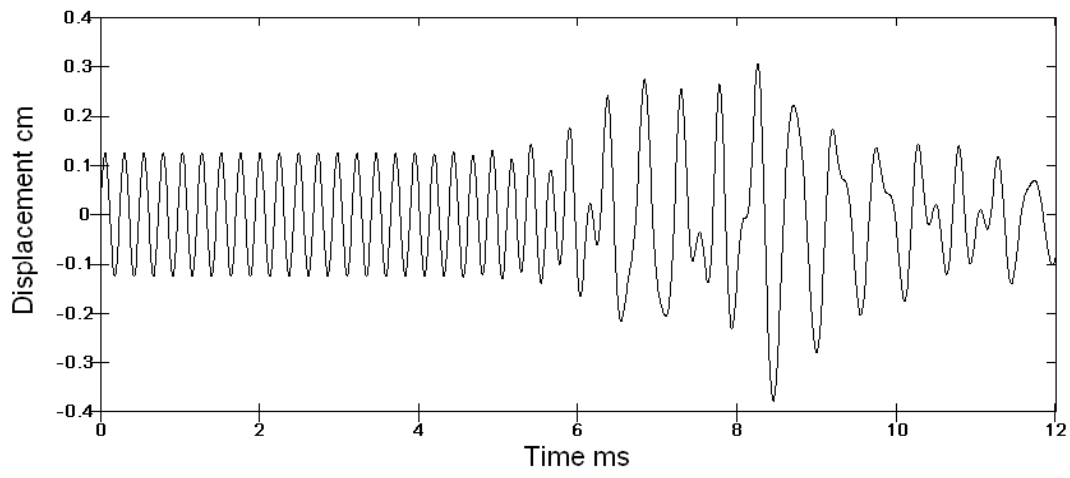

(a)

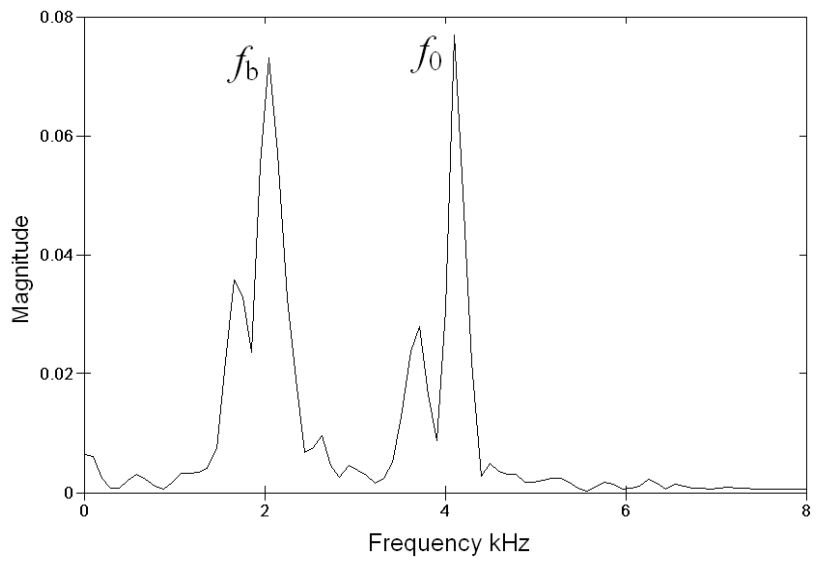

(b)

Fig. 3. 
ASME Journal of Pressure Vessel Technology

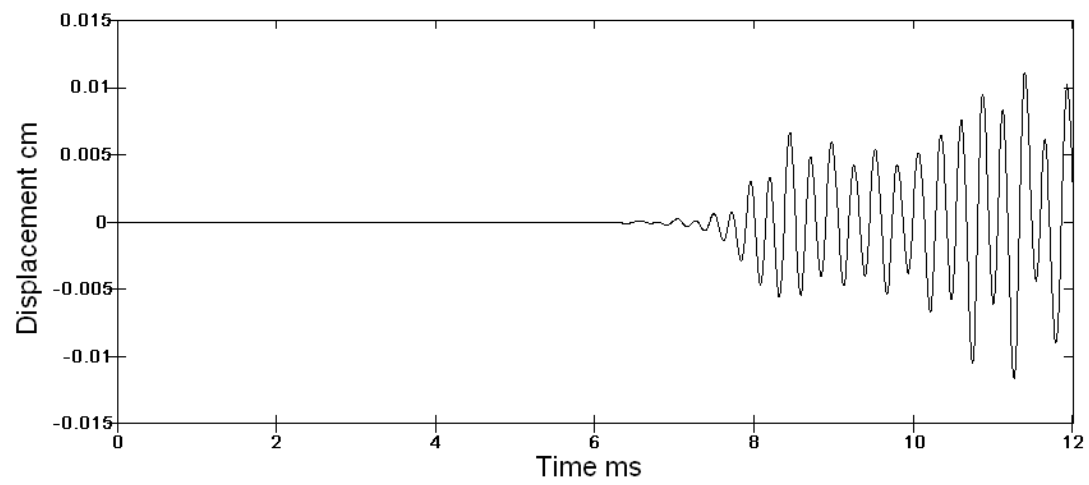

Fig. 4. 
ASME Journal of Pressure Vessel Technology

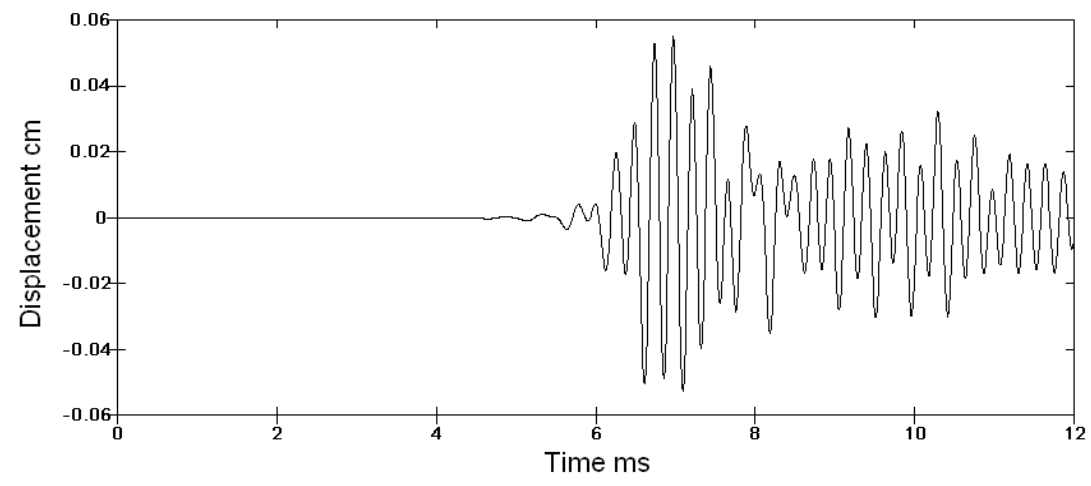

Fig. 5. 
ASME Journal of Pressure Vessel Technology

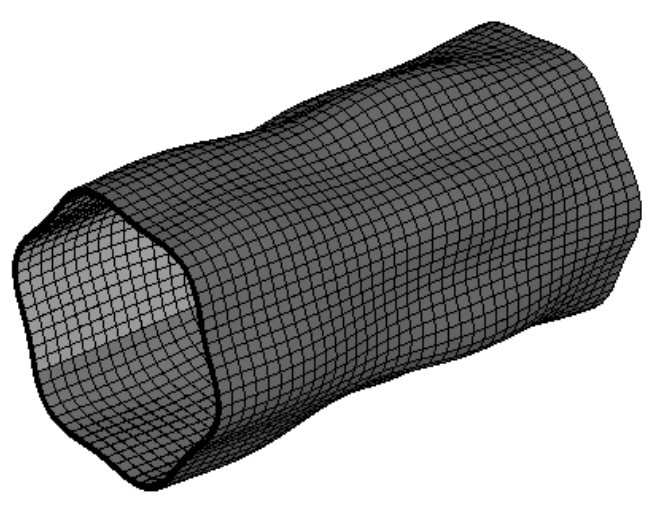

Fig. 6. 
ASME Journal of Pressure Vessel Technology

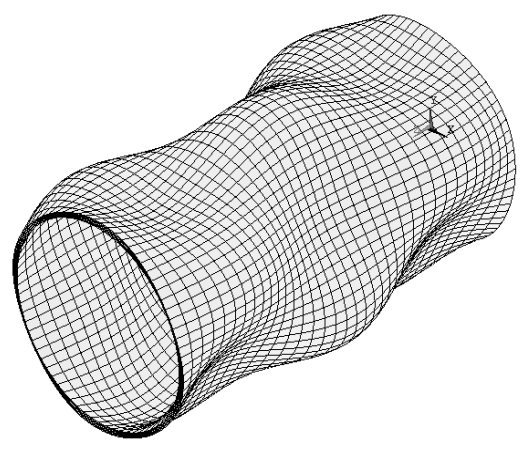

(a)

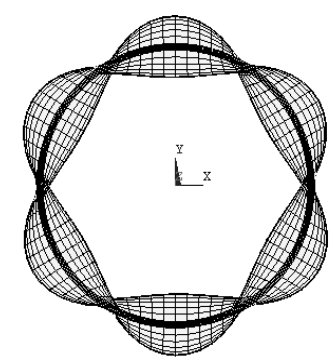

(b)

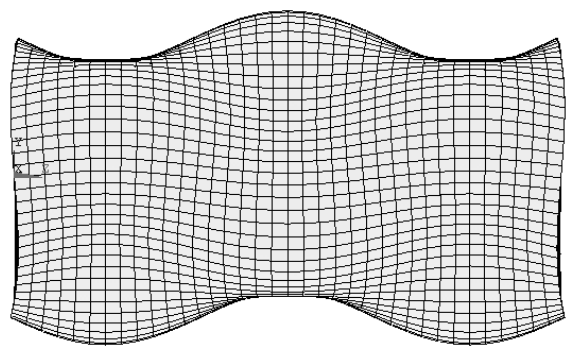

(c)

Fig. 7. 
ASME Journal of Pressure Vessel Technology

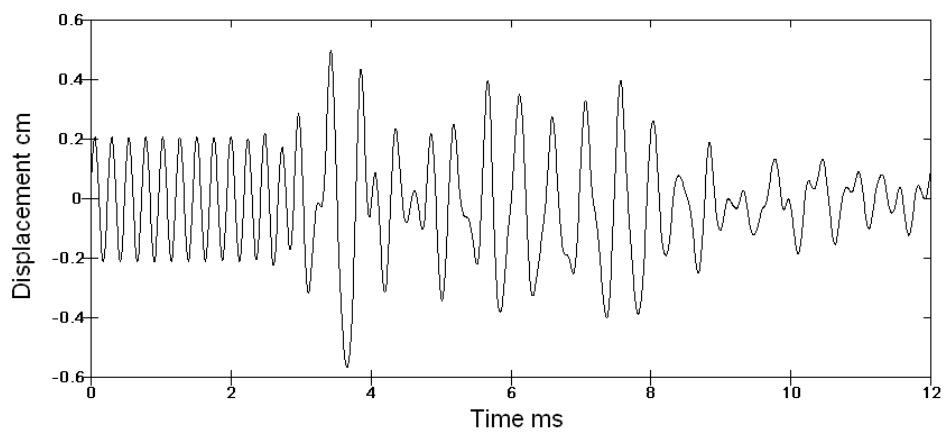

(a)

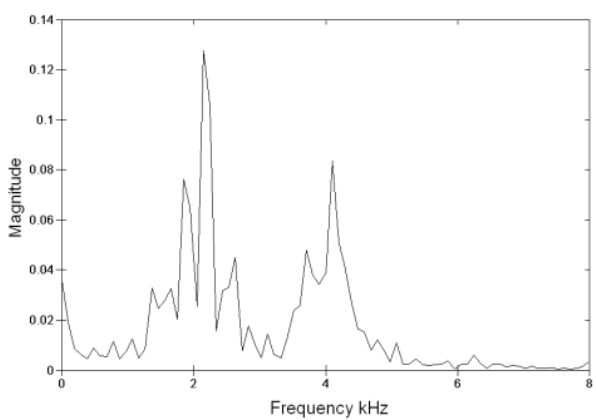

(b)

Fig.8. 


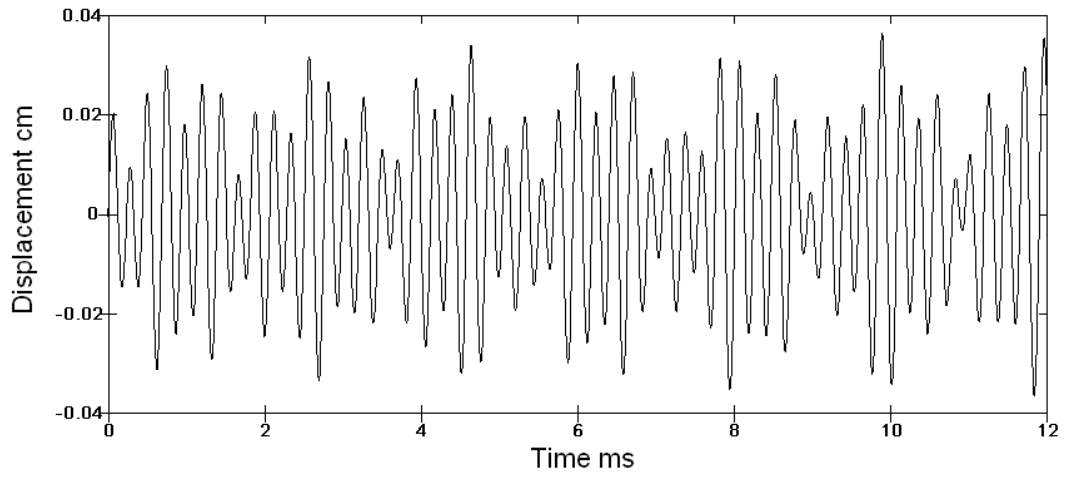

(a)

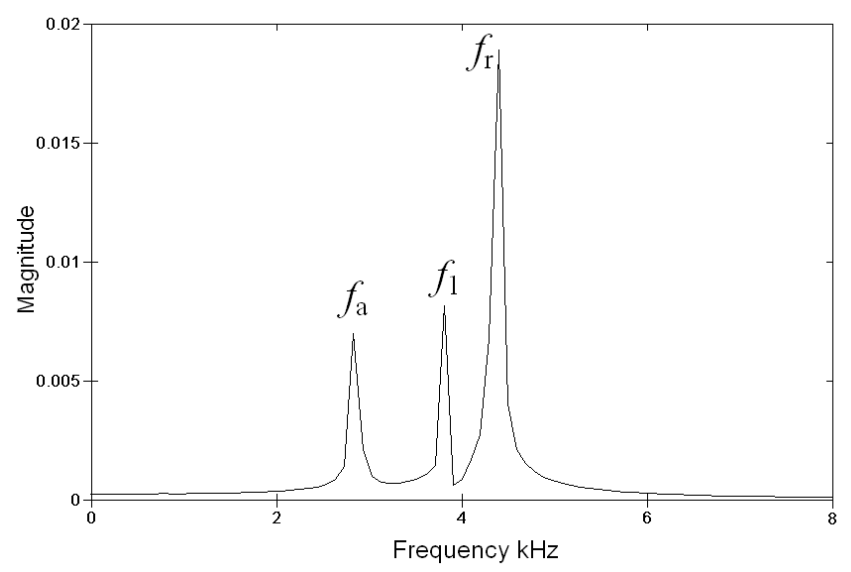

(b)

Fig. 9. 
ASME Journal of Pressure Vessel Technology

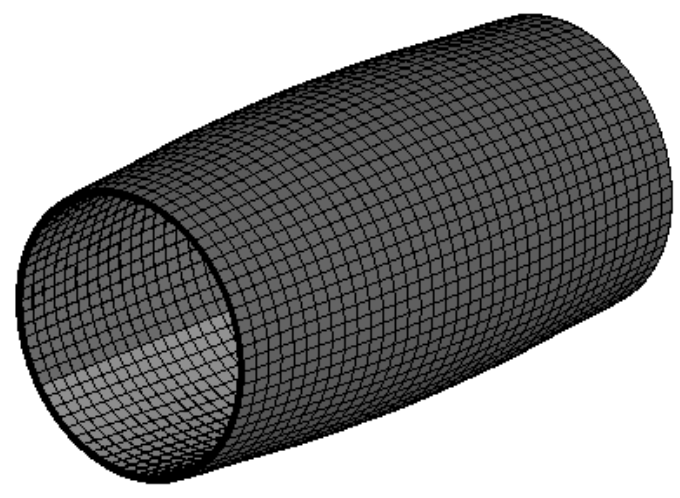

Fig. 10. 
ASME Journal of Pressure Vessel Technology

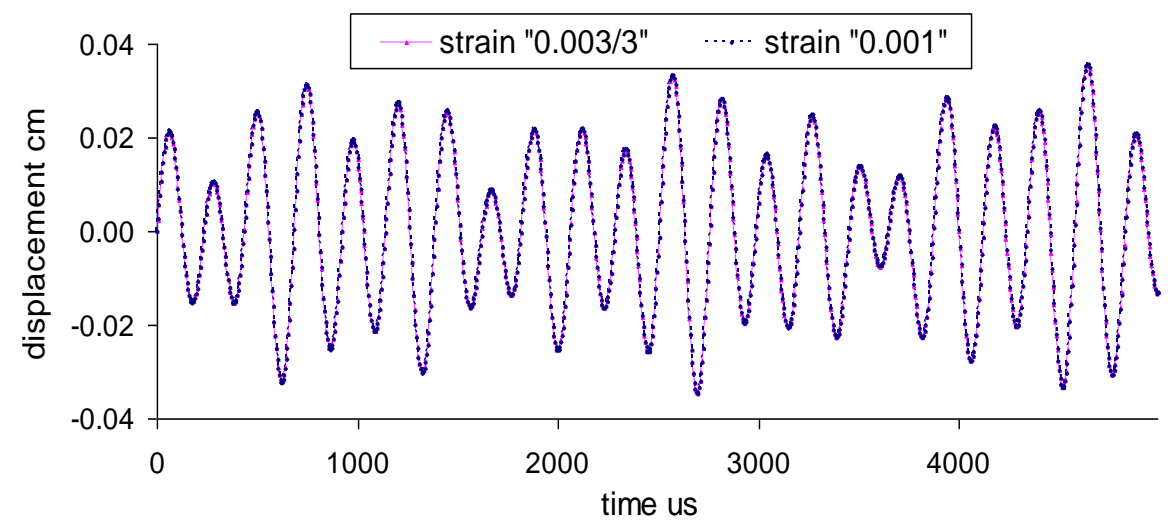

Fig. 11. 
ASME Journal of Pressure Vessel Technology

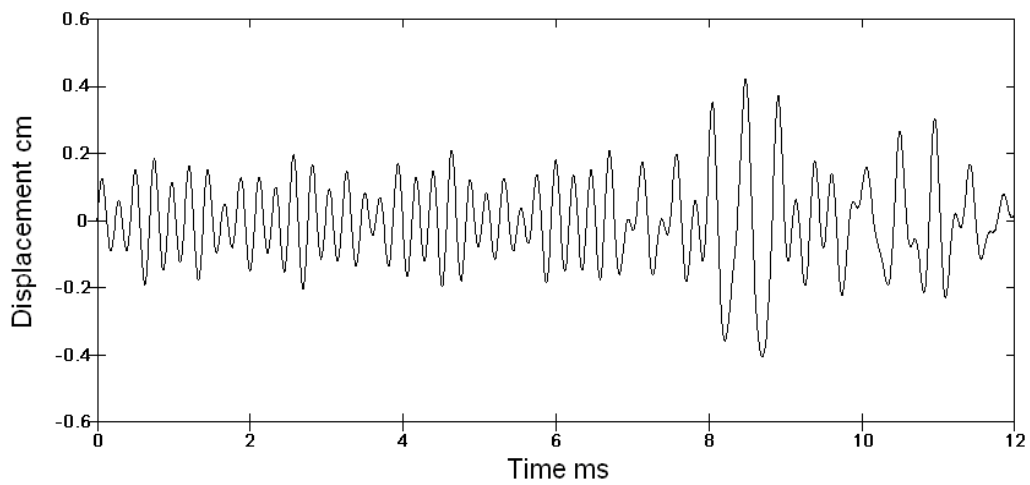

(a)

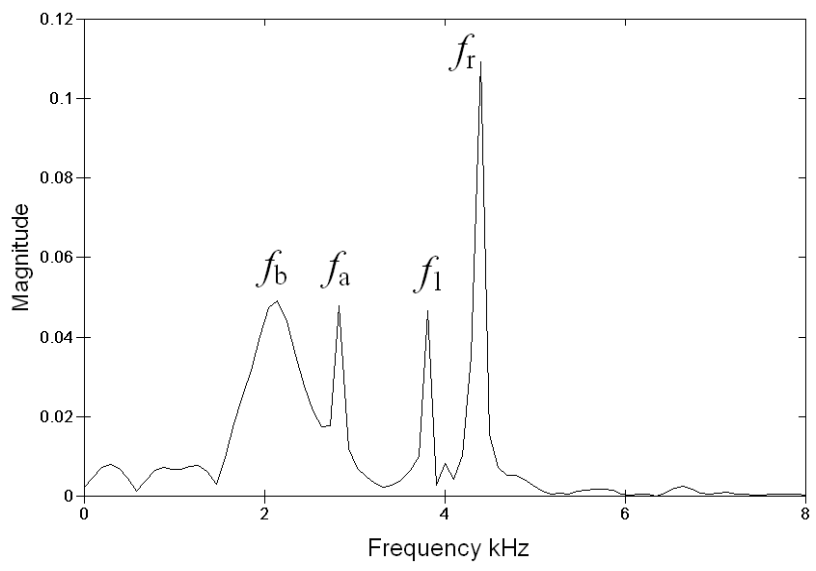

(b)

Fig. 12. 
ASME Journal of Pressure Vessel Technology

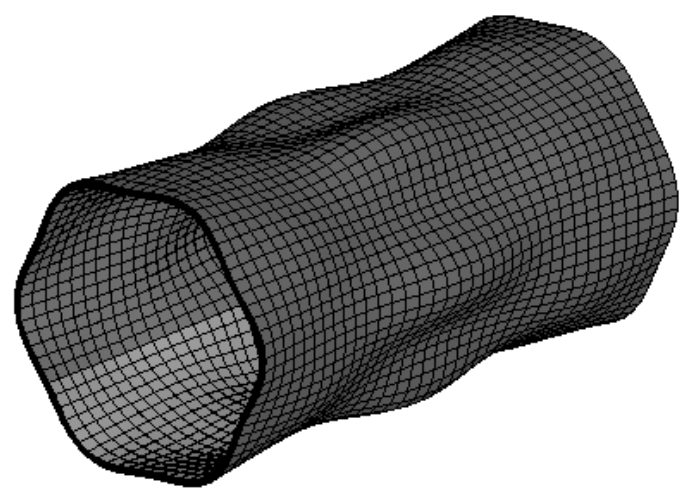

Fig. 13. 


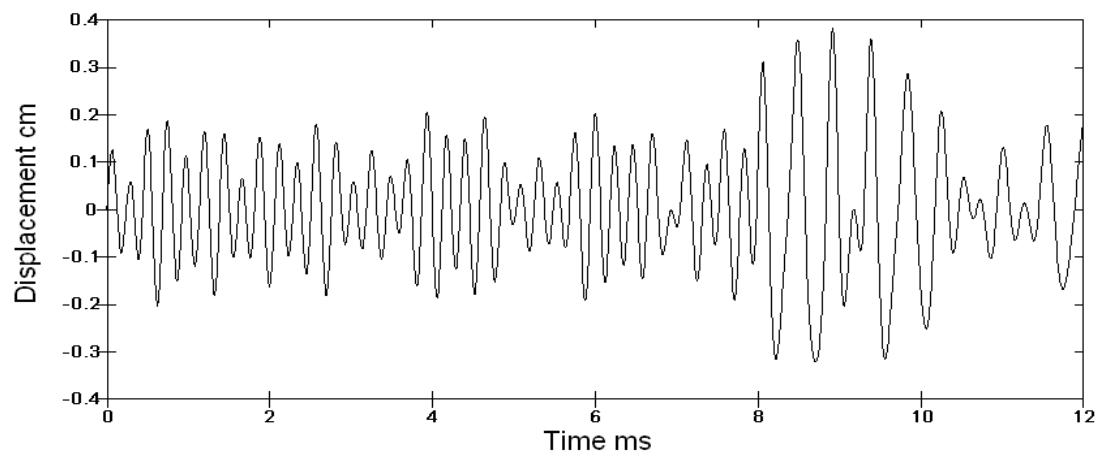

(a)

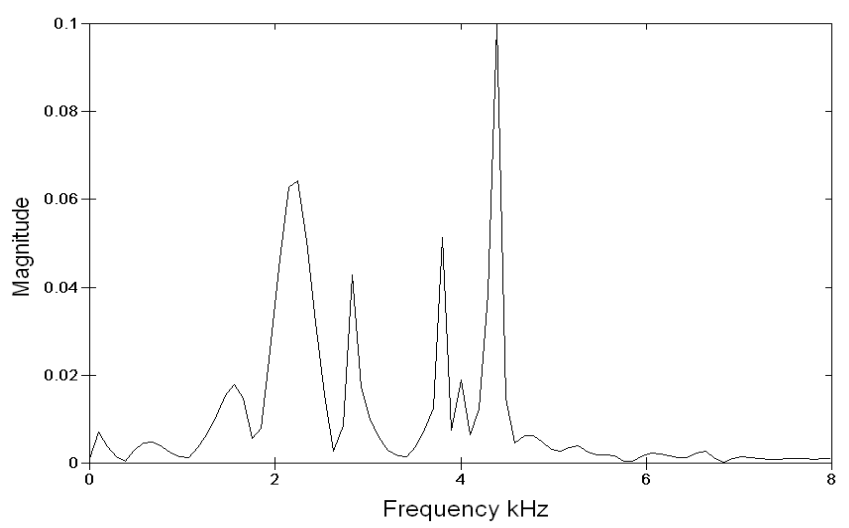

(b)

Fig. 14. 


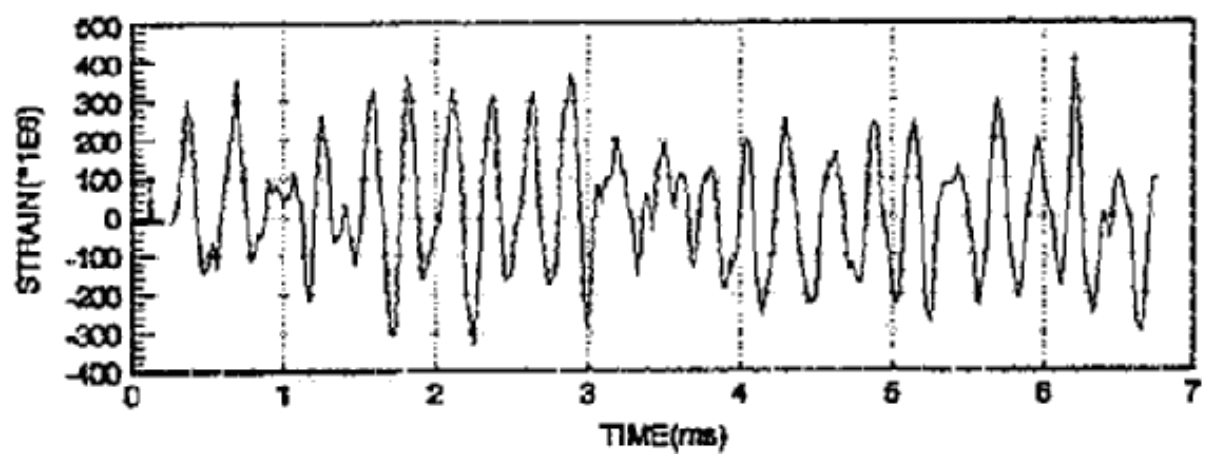

(a)

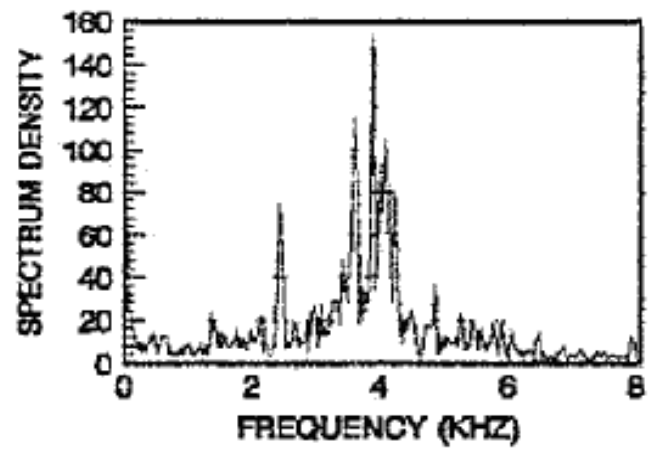

(b)

Fig.15. 


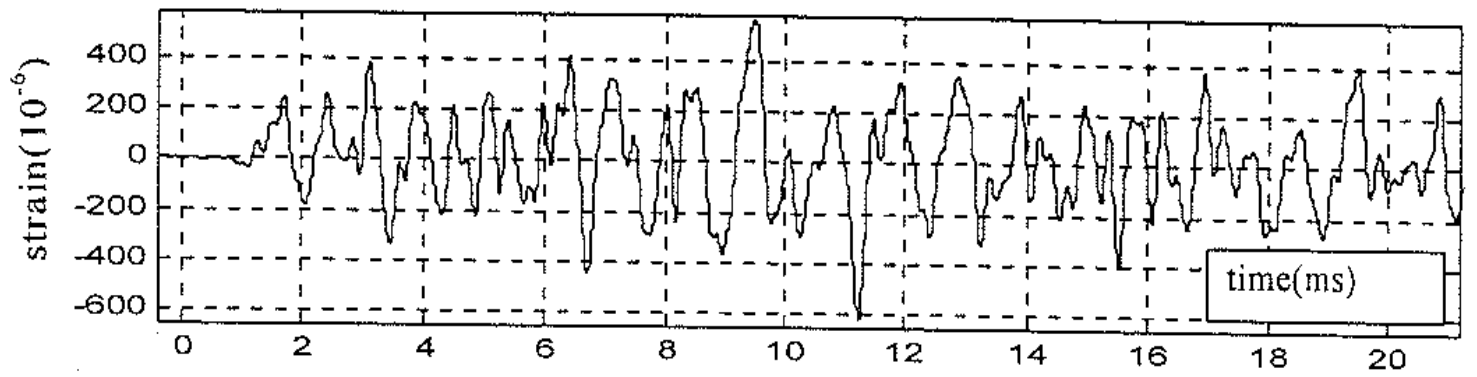

(a)

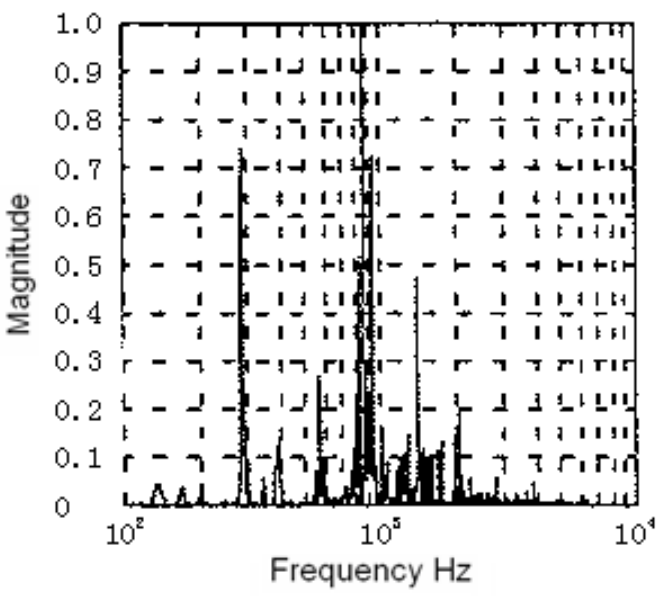

(b)

Fig.16. 
ASME Journal of Pressure Vessel Technology

Table 1

Young's modulus $E$

Poisson's ratio $v$

Density $\rho$

$210 \mathrm{GPa}$

0.333

$7.83 \mathrm{~g} / \mathrm{cm}^{3}$ 
ASME Journal of Pressure Vessel Technology

Table 2

Length $L$

Radius of centre line $a$

Thickness $h$

$852 \mathrm{~mm}$

$212.8 \mathrm{~mm}$

$9.8 \mathrm{~mm}$ 
Table 3

\begin{tabular}{ccccc}
\hline $\begin{array}{c}\text { First peak radial } \\
\text { displacement }\end{array}$ & First peak & Maximum radial & Strain growth & Strain growth \\
& strain & displacement & Factor & time \\
\hline $0.126 \mathrm{~cm}$ & 0.006 & $0.377 \mathrm{~cm}$ & 2.992 & $8.45 \mathrm{~ms}$ \\
\hline $0.168 \mathrm{~cm}$ & 0.008 & $0.437 \mathrm{~cm}$ & 2.601 & $4.63 \mathrm{~ms}$ \\
\hline $0.212 \mathrm{~cm}$ & 0.010 & $0.589 \mathrm{~cm}$ & 2.778 & $3.65 \mathrm{~ms}$ \\
\hline
\end{tabular}


ASME Journal of Pressure Vessel Technology

Table 4

First peak radial displacement
Maximum radial

displacement
Strain growth Factor 
Table 5

\begin{tabular}{ccccc}
\hline $\begin{array}{c}\text { First peak radial } \\
\text { displacement }\end{array}$ & First peak & Maximum radial & Strain growth & Strain growth \\
& strain & displacement & Factor & time \\
\hline $0.126 \mathrm{~cm}$ & 0.006 & $0.424 \mathrm{~cm}$ & 3.365 & $8.49 \mathrm{~ms}$ \\
\hline $0.168 \mathrm{~cm}$ & 0.008 & $0.586 \mathrm{~cm}$ & 3.488 & $5.91 \mathrm{~ms}$ \\
\hline $0.210 \mathrm{~cm}$ & 0.010 & $0.732 \mathrm{~cm}$ & 3.486 & $4.33 \mathrm{~ms}$ \\
\hline
\end{tabular}

